\title{
Therapeutic index of lymphadenectomy among patients with pancreatic neuroendocrine tumors: A multi-institutional analysis
}

\author{
Lu Wu MD ${ }^{1,2}$ | Kota Sahara MD ${ }^{2,3}$ | Diamantis I. Tsilimigras $M^{2} D^{2}$ | \\ Shishir K. Maithel MD ${ }^{4}$ | George A. Poultsides MD ${ }^{5}$ | Flavio G. Rocha MD \\ Sharon M. Weber $M^{7}$ | Ryan C. Fields $M^{8} D^{8}$ | Kamran Idrees $M^{9}$ | \\ Clifford S. Cho MD ${ }^{10}$ | Feng Shen MD ${ }^{1}$ | Timothy M. Pawlik MD, MPH, PhD, FACS ${ }^{2}$ (1) | \\ and other members of the U.S. Neuroendocrine Tumor Study Group
}

${ }^{1}$ Department of Hepatic Surgery, Eastern Hepatobiliary Surgery Hospital, Shanghai, China

${ }^{2}$ Department of Surgery, Division of Surgical Oncology, The Ohio State University Wexner Medical Center, Columbus, Ohio

${ }^{3}$ Department of Gastroenterological Surgery, Yokohama City University School of Medicine, Yokohama, Japan

${ }^{4}$ Department of Surgery, Emory University, Atlanta, GA

${ }^{5}$ Department of Surgery, Stanford University, Stanford, CA

${ }^{6}$ Department of Surgery, Virginia Mason Medical Center, Seattle, Washington

${ }^{7}$ Department of Surgery, University of Wisconsin School of Medicine and Public Health, Madison, Wisconsin

${ }^{8}$ Department of Surgery, Washington University School of Medicine, St. Louis, Missouri

${ }^{9}$ Division of Surgical Oncology, Department of Surgery, Vanderbilt University, Nashville, Tennessee

${ }^{10}$ Division of Hepatopancreatobiliary and Advanced Gastrointestinal Surgery, Department of Surgery, University of Michigan, Ann Arbor, Michigan

\section{Correspondence}

Timothy M. Pawlik, MD, MPH, PhD, FACS, FRACS (Hon), Division of Surgical Oncology, Department of Surgery, James Comprehensive Cancer Center, Wexner Medical Center, The Ohio State University, 395 W 12th Ave, Suite 670, Columbus, $\mathrm{OH} 43210$.

Email:Tim.Pawlik@osumc.edu

\begin{abstract}
Background: The benefit derived from lymph node dissection (LND) in patients with pancreatic neuroendocrine tumors ( $p N E T s$ ) based on clinicopathological characteristics remains unclear.

Methods: Patients undergoing surgery for pNET between 1997 and 2016 were identified using a multi-institutional dataset. The therapeutic index of LND relative to patient characteristics was calculated.

Results: Among 647 patients, the median number of lymph nodes (LNs) evaluated was 10 (interquartile range: 4-16) and approximately one quarter of patients had lymph node metastasis (LNM) ( $\mathrm{N}=159,24.6 \%)$. Among patients with LNM, 5-year recurrence-free survival was $56.0 \%$, reflecting a therapeutic index value of 13.8 . The therapeutic index was highest among patients with a moderately/poorly-differentiated pNET (21.5), Ki-67 $\geq 3 \%$ (20.1), tumor size $\geq 2.0 \mathrm{~cm}$ (20.0), and tumor location at the head of the pancreas (20.0). Patients with $\geq 8 \mathrm{LNs}$ evaluated had a higher therapeutic index than patients who had 1 to 7 LNs evaluated ( $\geq 8$ : 17.9 vs 1-7: 7.5; difference of index: 11.4).

Conclusion: LND was mostly beneficial among patients with pNETs $>2 \mathrm{~cm}$, Ki$67 \geq 3 \%$, and lesions located at the pancreatic head as identification of LNM was most common among individuals with these tumor characteristics. Evaluation of $\geq 8 \mathrm{LNs}$ was associated with a higher likelihood of identifying LNM as well as a higher therapeutic index, and therefore this number of LNs should be considered the goal.
\end{abstract}

KEYWORDS

lymphadenectomy, pancreatic neuroendocrine tumor, therapeutic index 


\section{1 | INTRODUCTION}

Pancreatic neuroendocrine tumors (pNETs) are rare neoplasms of the gastrointestinal tract with a rising incidence in the United States. ${ }^{1,2}$ Resection is the mainstay of treatment among patients with resectable pNETs although several nonsurgical techniques have been employed. ${ }^{3-5}$ While lymphadenectomy is typically performed at the time of resection to stage the disease, the role of routine lymph node dissection (LND) and the associated oncological therapeutic benefit remain controversial. ${ }^{4}$ For example, while data from a singleinstitution cohort of 136 patients with pNET reported that lymph node metastasis (LNM) was associated with shorter disease-free survival (DFS), ${ }^{6}$ a separate population-based study of 3851 patients demonstrated that nodal status was not necessarily associated with overall survival (OS). ${ }^{7}$ In light of these data, several investigators have questioned the benefit of routine LND in the treatment of patients with nonfunctional pNET and a $\mathrm{Ki}-67<3 \%{ }^{8}$ In fact, one recent study noted that patients who had a pNET $\leq 2.0 \mathrm{~cm}$ and a $\mathrm{Ki}-$ $67<3 \%$ in the distal pancreas had an incidence of LNM as low as $3.4 \%$ and, therefore, questioned the need for routine LND. ${ }^{9}$

While many studies support the predictive role of LNM and therefore the role of LND, robust evidence is lacking to support an actual therapeutic benefit for routine LND in pNET patients with resectable disease. ${ }^{4}$ To this end, Sasako et $\mathrm{al}^{10}$ have suggested using the "therapeutic index" as a means to determine any potential survival benefit associated with LND among patients undergoing surgical resection. The rationale of the therapeutic index is to identify patients who are most likely to have LNM and, therefore, derive a benefit from LND. ${ }^{10}$ The therapeutic index concept has been examined and validated for several other cancers including gastric, colorectal, cholangiocarcinoma, and lung. ${ }^{10-14}$ Nevertheless, to date, no study has assessed the therapeutic value of LND among patients with pNETs. As such, the objective of the current study was to define the therapeutic index of LND among patients undergoing resection of pNETs. In particular, we sought to identify preoperative patient factors, as well as clinicopathologic features of pNETs, that were associated with the potential clinically relevant therapeutic benefit associated with LND.

\section{2 | METHODS}

\section{1 | Study population and data collection}

Patients who underwent pancreatectomy for pNETs between 1997 and 2016 were identified using a multi-institutional database from eight tertiary institutions (The Ohio State University Comprehensive Cancer Center, Columbus, OH; University of Michigan, Ann Arbor MI; Stanford University, Palo Alto, CA; Virginia Mason Medical Center, Seattle, WA; Winship Cancer Institute, Emory University, Atlanta, GA; Washington University, School of Medicine, St Louis, MO; University of Wisconsin, School of Medicine and Public Health, Madison, WI; Vanderbilt University, Nashville, TN). ${ }^{15}$ All patients included in the study had a histologically proven pNET and underwent a curative intent pancreatectomy along with LND. Patients with metastatic disease, as well as individuals with macroscopically positive surgical margins (R2 resection), missing follow-up data, and individuals who died within 30 days of surgery were excluded from the analysis. The study was approved by the Institutional Review Board of all participating institutions.

Patient demographics and clinicopathologic data included age, sex, race, American Society of Anesthesiologist (ASA) class, functional status, type of resection, tumor size, tumor location, tumor number, number of lymph nodes (LNs) examined, number of LNM, tumor grade, resection margin status, Ki-67 status, presence of lymphovascular or perineural invasion, and receipt of adjuvant therapy. Functional tumors were defined as lesions with hormone overproduction (ie, insulinoma, gastrinoma, somatostatinoma, and VIPoma). ${ }^{16}$ LND was defined as the removal of LNs from regional nodal stations. All resected specimens were submitted for histopathologic analysis by an experienced pathologist at each institution.

\subsection{Calculation of the therapeutic index}

The frequency of LNM was calculated by dividing the number of patients with LNM in a particular group by the total number of patients in that subgroup. ${ }^{14}$ The therapeutic index of LND was calculated by multiplying the frequency of LNM in a particular group by the 5 -year recurrence-free survival (RFS) rate of patients with LNM in that specific subgroup of patients, as previously reported ${ }^{17}$; the 5-year endpoint was based on previous studies. ${ }^{11,18,19}$ Similar to previous reports, a therapeutic index difference of more than 10 was considered meaningful. ${ }^{14,17,18}$

\section{3 | Statistical analysis}

Continuous and categorical variables were presented as median (interquartile range [IQR]) and frequency (\%), respectively. Logistic regression was utilized to detect independent predictors of LNM. RFS was defined as the time duration from the date of surgery to tumor recurrence. Recurrence was defined as identification of suspicious imaging findings or biopsy-proven tumor. OS was calculated from the date of surgery to date of death or last followup. Survival curves were estimated using the Kaplan-Meier method and differences between curves were investigated with the logrank test. Statistical significance was assessed at $\alpha=.05$. All statistical analyses were performed using SPSS, version 25 (IBM Corp, Armonk, NY).

\section{3 | RESULTS}

\section{1 | Characteristics of patients undergoing lymphadenectomy}

Among 1125 patients who underwent curative-intent resection of pNETs, 647 (57.5\%) patients underwent LND and were included in the final analysis (Table 1). Median patient age at the time of surgery 
TABLE 1 Demographic and patient characteristics in the entire cohort $(n=647)$

\begin{tabular}{|c|c|}
\hline Variable & N (\%) \\
\hline Age, median (IQR) & $58(48-66)$ \\
\hline \multicolumn{2}{|l|}{ Sex } \\
\hline Male & $343(53.0 \%)$ \\
\hline Female & 304 (47.0\%) \\
\hline \multicolumn{2}{|l|}{ Race } \\
\hline White & $480(80.7 \%)$ \\
\hline African American & $51(8.6 \%)$ \\
\hline Asian & $39(6.6 \%)$ \\
\hline Hispanic & $23(3.8 \%)$ \\
\hline Other & $2(0.3 \%)$ \\
\hline \multicolumn{2}{|l|}{ ASA classification } \\
\hline 1 & $11(1.8 \%)$ \\
\hline 2 & $273(43.8 \%)$ \\
\hline 3 & $328(52.6 \%)$ \\
\hline 4 & 12 (1.8\%) \\
\hline \multicolumn{2}{|l|}{ Tumor functional status } \\
\hline Nonfunctional & 559 (88.0\%) \\
\hline Functional & 76 (12.0\%) \\
\hline \multicolumn{2}{|l|}{ Symptomatic } \\
\hline No & 273 (43.0\%) \\
\hline Yes & $362(57.0 \%)$ \\
\hline \multicolumn{2}{|l|}{ Type of resection } \\
\hline Enucleation & $28(4.3 \%)$ \\
\hline Classic PD & 76 (11.7\%) \\
\hline Pylorus-preserving PD & $129(19.9 \%)$ \\
\hline Central pancreatectomy & $10(1.5 \%)$ \\
\hline Distal pancreatectomy & $392(60.6 \%)$ \\
\hline Total pancreatectomy & $12(1.9 \%)$ \\
\hline \multicolumn{2}{|l|}{ Surgical approach } \\
\hline Open & 491 (75.9\%) \\
\hline MIS & $156(24.1 \%)$ \\
\hline \multicolumn{2}{|l|}{ Primary location } \\
\hline Head & $261(40.4 \%)$ \\
\hline Body/tail & 385 (59.6\%) \\
\hline Largest tumor size $(\mathrm{cm})$, median (IQR) & $2.2(1.4-3.8)$ \\
\hline \multicolumn{2}{|l|}{ Tumor number } \\
\hline Single & 590 (92.0\%) \\
\hline Multiple & $51(8.0 \%)$ \\
\hline Presence of $L N$ metastasis & $159(24.6 \%)$ \\
\hline Number of LN examined, median (IQR) & $10(4-16)$ \\
\hline Number of LN metastasis, median (IQR) & $0(0-1)$ \\
\hline \multicolumn{2}{|l|}{ Margin status } \\
\hline RO & 537 (83.8\%) \\
\hline $\mathrm{R} 1$ & $104(16.2 \%)$ \\
\hline \multicolumn{2}{|l|}{ Tumor differentiation } \\
\hline Well-differentiated & 499 (86.6\%) \\
\hline Moderately differentiated & 63 (10.9\%) \\
\hline Poorly differentiated & $14(2.4 \%)$ \\
\hline \multicolumn{2}{|l|}{ Ki-67 } \\
\hline$<3 \%$ & $268(59.3 \%)$ \\
\hline $3 \%-20 \%$ & $165(36.5 \%)$ \\
\hline$>20 \%$ & $19(4.2 \%)$ \\
\hline
\end{tabular}

(Continues)
TABLE 1 (Continued)

\begin{tabular}{|lc|}
\hline Variable & N (\%) \\
\hline $\begin{array}{l}\text { Lymphovascular invasion } \\
\text { Absent }\end{array}$ & $370(66.4 \%)$ \\
Present & $187(33.6 \%)$ \\
\hline Perineural invasion & \\
Absent & $408(75.7 \%)$ \\
Present & $131(24.3 \%)$ \\
\hline Adjuvant therapy & \\
No & $606(93.7 \%)$ \\
Yes & $41(6.3 \%)$ \\
\hline
\end{tabular}

Abbreviations: ASA, American Society of Anesthesiologist; IQR, interquartile range; LN, lymph node; MIS, minimally invasive surgery; PD, pancreatoduodenectomy .

was 58 years old (IQR: 48-66); roughly one-half of patients were male $(\mathrm{N}=343,53.0 \%)$ and had an ASA score of $3(\mathrm{~N}=328,52.6 \%)$. Most patients were white ( $\mathrm{N}=480,80.7 \%$ ), had a nonfunctional tumor $(\mathrm{N}=559,88.0 \%)$ and a tumor located in the body or tail of the pancreas $(\mathrm{N}=385,59.6 \%)$, and underwent a distal pancreatectomy $(\mathrm{N}=392,60.6 \%)$ through an open surgical approach ( $\mathrm{N}=491,75.9 \%)$. Most patients had unifocal disease $(\mathrm{N}=590,92.0 \%)$ and median tumor size of $2.2 \mathrm{~cm}$ (IQR: 1.4-3.8). The median number of LNs evaluated was 10 (IQR: 4-16) and approximately one-quarter of patients had LNM (N=159, 24.6\%). Most patients underwent an RO resection ( $N=537,83.8 \%$ ) (Table 1$)$.

\section{2 | Preoperative factors associated with LNM}

On bivariate analysis, male sex (odds ratio [OR], 1.54, 95\% confidence interval $[\mathrm{Cl}], 1.07-2.22$ ), functional pNET status (OR, 0.48; 95\% Cl, 0.25-0.94), symptomatic pNET (OR, 1.53; 95\% Cl, 1.052.23), primary location of tumor in the head of pancreas (OR, 2.41; 95\% Cl, 1.67-3.47), tumor size $\geq 2.0 \mathrm{~cm}(\mathrm{OR}, 5.90$; 95\% Cl, 3.78-9.21), number of $\mathrm{LNs}$ evaluated $\geq 8$ (OR, 3.04; $95 \% \mathrm{Cl}, 1.99-4.64$ ), moderately (OR, $2.78 ; 95 \% \mathrm{Cl}, 1.62-4.79)$ or poorly differentiated (OR, 6.67; 95\% Cl, 2.19-20.33) tumors, and Ki-67 between 3\% and $20 \%$ (OR, 3.34; 95\% Cl, 2.11-5.30), or Ki-67 > 20\% (OR, 7.84; 95\% Cl, 2.97-20.69) were associated with LNM. On multivariable analysis, only the presence of symptoms (OR, 2.03; 95\% Cl, 1.17-3.51), primary tumor in head of pancreas (OR, 1.83; $95 \% \mathrm{Cl}, 1.10-3.06)$, tumor size $\geq 2.0 \mathrm{~cm}(\mathrm{OR}, 4.59 ; 95 \% \mathrm{Cl}, 2.57-8.20)$, and $\mathrm{Ki}-67$ between $3 \%$ and $20 \%$ (OR, 1.83; $95 \% \mathrm{Cl}, 1.04-3.22)$ remained associated with a higher likelihood of LNM (Table 2).

\section{3 | Survival and therapeutic index by preoperative factors}

After a median follow-up of 33.9 months (IQR: 11.9-62.6), 5-year OS was $84.1 \%(95 \% \mathrm{Cl}, 74.9-90.3)$ among patients with LNM vs $93.8 \%$ 
TABLE 2 Logistic regression analysis of clinicopathological factors associated with lymph node metastasis

\begin{tabular}{|c|c|c|c|c|}
\hline \multirow[b]{2}{*}{ Variable } & \multicolumn{2}{|c|}{ Bivariate analysis } & \multicolumn{2}{|c|}{$\begin{array}{l}\text { Multivariable } \\
\text { analysis }\end{array}$} \\
\hline & OR & $95 \% \mathrm{Cl}$ & OR & $95 \% \mathrm{Cl}$ \\
\hline \multicolumn{5}{|l|}{ Age } \\
\hline$<65$ & Ref & - & - & - \\
\hline$\geq 65$ & 0.95 & $0.63-1.42$ & - & - \\
\hline \multicolumn{5}{|l|}{ Sex } \\
\hline Female & Ref & - & Ref & - \\
\hline Male & 1.54 & $1.07-2.22$ & 1.50 & $0.90-2.52$ \\
\hline \multicolumn{5}{|l|}{ Functional status } \\
\hline Nonfunctional & Ref & - & Ref & - \\
\hline Functional & 0.48 & $0.25-0.94$ & 0.43 & $0.17-1.07$ \\
\hline \multicolumn{5}{|l|}{ Symptomatic } \\
\hline No & Ref & - & Ref & - \\
\hline Yes & 1.53 & $1.05-2.23$ & 2.03 & $1.17-3.51$ \\
\hline \multicolumn{5}{|l|}{ Primary location } \\
\hline Body/tail & Ref & - & Ref & - \\
\hline Head & 2.41 & $1.67-3.47$ & 1.83 & $1.10-3.06$ \\
\hline \multicolumn{5}{|l|}{ Tumor size, $\mathrm{cm}$} \\
\hline$<2.0$ & Ref & - & Ref & - \\
\hline$\geq 2.0$ & 5.90 & $3.78-9.21$ & 4.59 & $2.57-8.20$ \\
\hline \multicolumn{5}{|l|}{ Tumor number } \\
\hline Single & Ref & - & - & - \\
\hline Multiple & 0.72 & $0.35-1.48$ & - & - \\
\hline \multicolumn{5}{|c|}{ Number of LN examined } \\
\hline $1-7$ & Ref & - & Ref & - \\
\hline$\geq 8$ & 3.04 & $1.99-4.64$ & 1.61 & $0.90-2.90$ \\
\hline \multicolumn{5}{|l|}{ Tumor differentiation } \\
\hline Well-differentiated & Ref & - & Ref & - \\
\hline $\begin{array}{l}\text { Moderately } \\
\text { differentiated }\end{array}$ & 2.78 & $1.62-4.79$ & 1.80 & $0.85-3.80$ \\
\hline $\begin{array}{l}\text { Poorly } \\
\text { differentiated }\end{array}$ & 6.67 & $2.19-20.33$ & 0.96 & $0.10-9.59$ \\
\hline \multicolumn{5}{|l|}{ Ki-67 } \\
\hline$<3 \%$ & Ref & - & Ref & - \\
\hline $3 \%-20 \%$ & 3.34 & $2.11-5.30$ & 1.83 & $1.04-3.22$ \\
\hline$>20 \%$ & 7.84 & $2.97-20.69$ & 2.28 & $0.37-14.03$ \\
\hline
\end{tabular}

Abbreviations: $\mathrm{Cl}$, confidence interval; $\mathrm{LN}$ : lymph node; OR, odds ratio.

(95\% Cl, 90.1-96.1) among patients with negative LNs $(P<.001$; Figure 1A). Similarly, 5-year RFS was $56.0 \%$ (95\% Cl, 44.7-66.7) vs 83.3\% (95\% Cl, 77.9-87.6) among patients who did and did not have LNM, respectively $(P<.001$; Figure $1 \mathrm{~B})$.

Irrespective of other factors, patients with poor to undifferentiated tumor grade had the worst 5-year RFS (46.0\%) followed by symptomatic patients (49.3\%) (Table 3). The highest therapeutic value of lymphadenectomy was noted among patients with moderately to poorly differentiated tumor grade (21.5), Ki-67 $\geq 3 \%$ (20.1), tumor size $\geq 2.0 \mathrm{~cm}$ (20.0), and primary tumor location in the head of the pancreas (20.0). An index difference of more than 10 points was noted when examining tumor size (index difference: 13.4 ; $<2.0$ : 6.6 vs 22.0: 20.0), Ki-67 (index difference: 12.6 ; <3\%: 7.5 vs $\geq 3 \%$ : 20.1), location of tumor (index difference: 10.3; body/tail: 9.7 vs head: 20.0) as well as the number of LNs evaluated (index difference: 10.4; 1-7:
7.5 vs $\geq 8: 17.9$ ) (Table 3 ). Of note, patients who had $\geq 8 \mathrm{LNs}$ evaluated had a higher therapeutic index than patients who had 1 to $7 \mathrm{LNs}$ evaluated ( $\geq 8$ : 17.9 vs 1-7: 7.5 ; difference of index: 11.4 ).

\section{4 | DISCUSSION}

The prognostic impact of LNM and the therapeutic role of LND to remove LNM among patients with pNETs remain a topic of debate. Several studies have reported that LNM was not associated with OS among patients undergoing resection of $\mathrm{pNET}$, $^{7,20}$ While several other studies reported that the presence of LNM was associated with worse RFS, ${ }^{6,21,22}$ other investigators have noted that 5- and 10-year OS were comparable among patients who did and did not have LNM.,22 As such, the therapeutic value of routine LND still remains controversial among patients undergoing surgery for pNETs, despite the possibility that removal of LNM may decrease locoregional recurrence. ${ }^{4}$ The current study was important because we identified patients who may have the most benefit from LND by calculating the therapeutic index on the basis of clinicopathological characteristics. ${ }^{10}$ Of note, a difference in the therapeutic index above 10 was identified among patients who had a tumor size larger than $2 \mathrm{~cm}(\geq 2: 20.0$ vs <2: 6.6; difference of index: 13.4 ), patients who had a Ki-67 $\geq 3 \%$ ( $\geq 3 \%: 20.1$ vs $<3 \%$; difference of index: 12.6), as well as patients with a pNET located in the head of the pancreas (head: 20.0 vs body/tail: 9.7; difference of index: 10.3). Of note, the therapeutic index was also associated with the total number of nodes evaluated as patients who had $\geq 8$ LNs evaluated had a higher therapeutic index than patients who had 1 to 7 LNs evaluated. To the best of our knowledge, this is the first study to examine the therapeutic benefit associated with LND among patients who underwent a curative-intent resection for a pNET.

First proposed by Sasako et $\mathrm{al}^{10}$ the therapeutic index has been used in assessing the role of LND in the surgical management of gastric, rectal, ${ }^{11}$ esophageal, ${ }^{12}$ and lung cancer. ${ }^{13}$ In addition, our own group recently examined the therapeutic benefit associated with LND among patients with intrahepatic cholangiocarcinoma and identified particular groups of patients who were most likely to derive a benefit from LND. ${ }^{14,23}$ The rationale of the therapeutic index is that the utilization of LND would be most effective when it is employed among patients who have the highest risk for LNM and therefore have the greatest chance of a therapeutic benefit. ${ }^{10}$ Given the conflicting results about the role of LND for patients undergoing surgery for $\mathrm{pNET}$, the therapeutic index could be a relevant way to identify which specific subgroups of patients may particularly warrant LND. ${ }^{10}$ Indeed, the goal of LN harvesting may not only be the accurate staging, but also could act as a means to reduce locoregional disease among patients with LNM. To this end, the current study noted that certain clinicopathological characteristics were associated with a reasonable therapeutic index difference, including primary tumor location, tumor size, Ki-67, and number of LNs evaluated (Table 3). Of note, while 5 -year RFS was not different among these groups of patients, the higher rates of LNM in each particular subgroup of patients (ie, patients with tumor located at the 
(A)

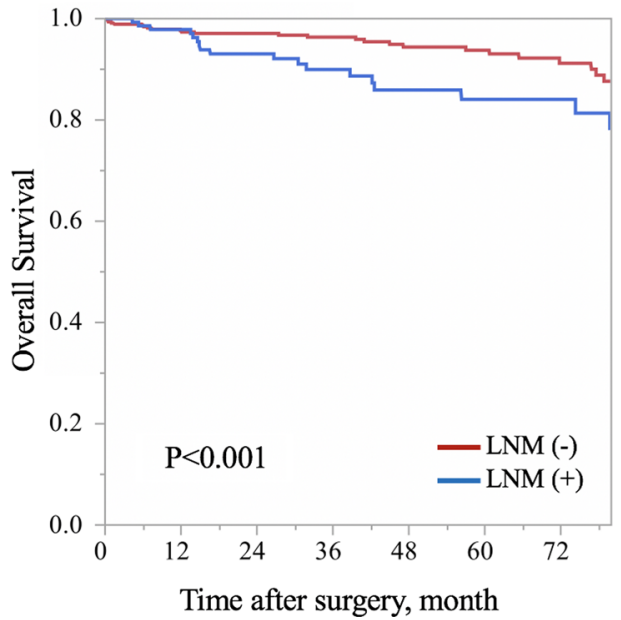

(B)

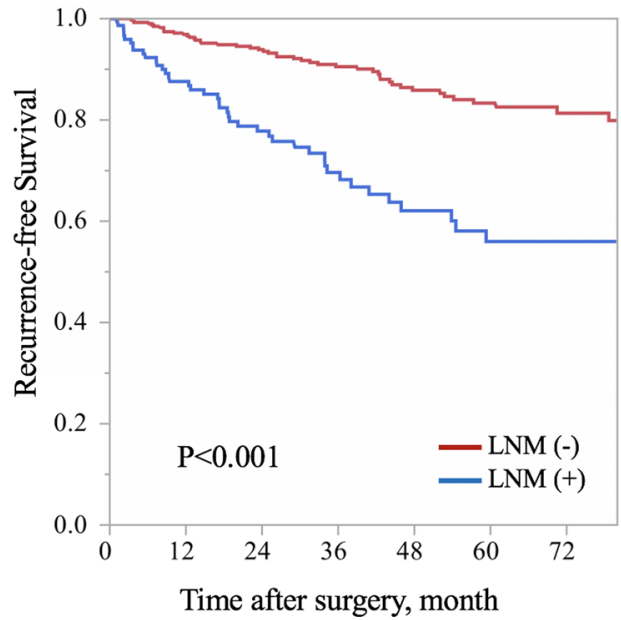

FIGURE 1 Kaplan-Meier curves demonstrating OS (A) and RFS (B) among patients who underwent LND stratified by the presence of LNM. LNM, lymph node metastasis; LND, lymph node dissection; OS, overall survival; RFS, recurrence-free survival [Color figure can be viewed at wileyonlinelibrary.com]

TABLE 3 Therapeutic index stratified by preoperative acquirable clinicopathological factors

\begin{tabular}{|c|c|c|c|c|}
\hline Variable & $\begin{array}{l}\text { Frequency } \\
\text { of LNM }\end{array}$ & $\begin{array}{l}5-y \\
\text { RFS, \% }\end{array}$ & $\begin{array}{l}\text { Therapeutic } \\
\text { index }\end{array}$ & $\begin{array}{l}\text { Difference } \\
\text { of index }\end{array}$ \\
\hline Overall & 0.246 & 56.0 & 13.8 & \\
\hline \multicolumn{5}{|c|}{ Functional status } \\
\hline Nonfunctional & 0.259 & 56.0 & 14.5 & 5.8 \\
\hline Functional & 0.145 & 60.0 & 8.7 & \\
\hline \multicolumn{5}{|l|}{ Symptomatic } \\
\hline No & 0.202 & 71.1 & 14.4 & 0.6 \\
\hline Yes & 0.279 & 49.3 & 13.8 & \\
\hline \multicolumn{5}{|l|}{ Primary location } \\
\hline Body/tail & 0.179 & 54.0 & 9.7 & \\
\hline Head & 0.345 & 58.0 & 20.0 & 10.3 \\
\hline \multicolumn{5}{|l|}{ Tumor size, cm } \\
\hline$<2.0$ & 0.094 & 69.9 & 6.6 & \\
\hline$\geq 2.0$ & 0.379 & 52.7 & 20.0 & 13.4 \\
\hline \multicolumn{5}{|l|}{ Tumor number } \\
\hline Single & 0.253 & 53.5 & 13.5 & \\
\hline Multiple & 0.196 & 85.7 & 16.8 & 2.7 \\
\hline \multicolumn{5}{|l|}{ Grade } \\
\hline Well & 0.212 & 60.2 & 12.8 & \\
\hline $\begin{array}{l}\text { Moderate to } \\
\text { poor }\end{array}$ & 0.468 & 46.0 & 21.5 & 8.7 \\
\hline \multicolumn{5}{|l|}{ Ki-67 } \\
\hline$<3 \%$ & 0.149 & 50.1 & 7.5 & \\
\hline$\geq 3 \%$ & 0.391 & 51.4 & 20.1 & 12.6 \\
\hline \multicolumn{5}{|c|}{ Number of LNs harvested } \\
\hline $1-7$ & 0.136 & 55.1 & 7.5 & \\
\hline$\geq 8$ & 0.323 & 55.4 & 17.9 & 10.4 \\
\hline
\end{tabular}

Abbreviations: LNM, lymph node metastasis; RFS, recurrence-free survival.

Bold values represent an index difference of more than 10, which was considered important. head of pancreas, LNM: $34.5 \%$; tumor size $\geq 2 \mathrm{~cm}$, LNM: $37.9 \%$; Ki$67>3 \%, 39.1 \%$ and >8 LN harvested, and LNM: $32.3 \%)$ led to a higher therapeutic index value (Table 3). The reason for the comparable RFS among these subgroups of patients may be that LND not only facilitated identification of LNM but also provided an oncological benefit for patients with seemingly worse characteristics (and higher LNM rates) by eliminating locoregional disease and reducing the risk of local recurrence. In addition, data from the current study demonstrated that an increase in the number of LNs evaluated was associated with a concomitant increase in the number of LNM detected. Specifically, removing $>8 \mathrm{LNs}$ was associated with a higher therapeutic index compared with harvesting seven or fewer LNs (index difference of more than 10), suggesting that eight LNs is the appropriate goal of LND threshold. ${ }^{24,25}$

Previous studies have attempted to evaluate the role of LND in pNET patients to identify subgroups of individuals who might benefit the most from LND. For example, Harimoto et $\mathrm{al}^{22}$ reported that the presence of LNM was associated with DFS, but not OS. In turn, these authors recommended that patients with $\mathrm{Ki}-67 \geq 3 \%$ should have routine LND since these patients were at high risk for locoregional recurrence. ${ }^{22}$ In a separate study, Lopez-Aguiar et $\mathrm{al}^{9}$ noted that less than $10 \%$ of patients with a tumor less than $2 \mathrm{~cm}$ had LNM; in addition, patients with a $\mathrm{Ki}-67<3 \%$ and pNET location in the distal pancreas had a particularly low risk of LNM (3.4\%). In line with these reports, data from our study suggested that LND could be more meaningful among patients with pNET $>2 \mathrm{~cm}$ and among patients with pNET located in the pancreatic head with $\mathrm{Ki}-67>3 \%$. As such, surgeons should weigh the potential benefit and related risks before deciding on the extent of LND. Data from the current study strongly suggest that routine LND and evaluation of $\geq 8 \mathrm{LNs}$ 
should be performed among these patients at high risk of LNM. In contrast, among patients with a tumor $<2 \mathrm{~cm}$ (therapeutic index: 6.6), Ki-67 $<3 \%$ (7.5) or pNET located at the pancreatic body or tail (9.7) the therapeutic benefit of LND appeared to be much more modest.

Several limitations should be taken into consideration when interpreting the results of the current study. Due to its retrospective nature, the current study may be subject to selection bias. In addition, while the multi-institutional database may serve to minimize the interinstitutional bias, the inclusion of multiple centers could have introduced some bias related to unstandardized surgical operations, pathological analysis of the surgical specimen, and variation of followup protocols at individual institutions. In addition, while the cut-off value of therapeutic index associated with LND has not been standardized, the value used in the current study facilitated comparison to the relative therapeutic value of LND among subgroups of patients who did or did not have certain characteristics. ${ }^{14}$

In conclusion, LND was mostly beneficial among patients with pNETs $>2 \mathrm{~cm}, \mathrm{Ki}-67 \geq 3 \%$, and lesions located at the pancreatic head as identification of LNM was most common among individuals with these tumor characteristics. In addition, evaluation of $\geq 8$ LNs was associated with a higher likelihood of identifying LNM, as well as a higher therapeutic index, and therefore this number of nodes should be considered the goal to evaluate.

\section{CONFLICT OF INTERESTS}

The authors declare that there are no conflict of interests.

\section{US NEUROENDOCRINE TUMOR STUDY GROUP}

Jordan Cloyd, Department of Surgery, Division of Surgical Oncology, The Ohio State University Wexner Medical Center and James Comprehensive Cancer Center, Columbus, Ohio; Mary Dillhoff, Department of Surgery, Division of Surgical Oncology, The Ohio State University Wexner Medical Center and James Comprehensive Cancer Center, Columbus, Ohio; Alexandra G. Lopez-Aguiar, Department of Surgery, Emory University, Atlanta, GA; Eleftherios Makris, Department of Surgery, Stanford University, Stanford, CA; Zaheer Kanji, Department of Surgery, Virginia Mason Medical Center, Seattle; Alexander Fisher, Department of Surgery, University of Wisconsin School of Medicine and Public Health, Madison, WI; Bradley A. Krasnick, Department of Surgery, Washington University School of Medicine, St Louis, MO; Paula M. Smith, Division of Surgical Oncology, Department of Surgery, Vanderbilt University, Nashville, TN; Megan Beems, Division of Hepatopancreatobiliary and Advanced Gastrointestinal Surgery, Department of Surgery, University of Michigan, Ann Arbor, MI

\section{DATA ACCESSIBILITY}

The data that support the findings of this study are available from the corresponding author upon reasonable request.

\section{ORCID}

Diamantis I. Tsilimigras (D) http://orcid.org/0000-0002-3676-9263

Timothy M. Pawlik (D) http://orcid.org/0000-0002-7994-9870

\section{REFERENCES}

1. Dasari A, Shen C, Halperin D, et al. Trends in the incidence, prevalence, and survival outcomes in patients with neuroendocrine tumors in the United States. JAMA Oncol. 2017;3: 1335-1342.

2. Halfdanarson TR, Rabe KG, Rubin J, Petersen GM. Pancreatic neuroendocrine tumors (PNETs): incidence, prognosis and recent trend toward improved survival. Ann Oncol. 2008;19: 1727-1733.

3. Rindi G, Wiedenmann B. Neuroendocrine neoplasms of the gut and pancreas: new insights. Nat Rev Endocrinol. 2011;8:54-64.

4. Falconi M, Eriksson B, Kaltsas G, et al. ENETS consensus guidelines update for the management of patients with functional pancreatic neuroendocrine tumors and non-functional pancreatic neuroendocrine tumors. Neuroendocrinology. 2016;103:153-171.

5. Frilling A, Modlin IM, Kidd M, et al. Recommendations for management of patients with neuroendocrine liver metastases. Lancet Oncol. 2014;15:e8-e21.

6. Hashim YM, Trinkaus KM, Linehan DC, et al. Regional lymphadenectomy is indicated in the surgical treatment of pancreatic neuroendocrine tumors (PNETs). Ann Surg. 2014;259:197-203.

7. Bilimoria KY, Talamonti MS, Tomlinson JS, et al. Prognostic score predicting survival after resection of pancreatic neuroendocrine tumors: analysis of 3851 patients. Ann Surg. 2008;247: 490-500.

8. Yoo YJ, Yang SJ, Hwang HK, Kang CM, Kim H, Lee WJ. Overestimated oncologic significance of lymph node metastasis in G1 nonfunctioning neuroendocrine tumor in the left side of the pancreas. Medicine. 2015;94:e1404.

9. Lopez-Aguiar AG, Ethun CG, Zaidi MY, et al. The conundrum of $<2-\mathrm{cm}$ pancreatic neuroendocrine tumors: a preoperative risk score to predict lymph node metastases and guide surgical management. Surgery. 2019;166:15-21.

10. Sasako M, McCulloch P, Kinoshita T, Maruyama K. New method to evaluate the therapeutic value of lymph node dissection for gastric cancer. Br J Surg. 1995;82:346-351.

11. Ueno $H$, Mochizuki $H$, Hashiguchi $Y$, et al. Potential prognostic benefit of lateral pelvic node dissection for rectal cancer located below the peritoneal reflection. Ann Surg. 2007;245:80-87.

12. Soeno $\mathrm{T}$, Harada $\mathrm{H}$, Hosoda $\mathrm{K}$, et al. Lymph node progression and optimized node dissection of middle thoracic esophageal squamous cell carcinoma in the latest therapeutic surgical strategy. Ann Surg Oncol. 2019;26:996-1004.

13. Kuroda H, Sakao $\mathrm{Y}$, Mun M, et al. Lymph node metastases and prognosis in left upper division non-small cell lung cancers: the impact of interlobar lymph node metastasis. PLOS One. 2015; 10:e0134674.

14. Sahara K, Tsilimigras $\mathrm{DI}$, Merath $\mathrm{K}$, et al. Therapeutic index associated with lymphadenectomy among patients with intrahepatic cholangiocarcinoma: which patients benefit the most from nodal evaluation? Ann Surg Oncol. 2019;26:2959-2968.

15. Zhang XF, Wu Z, Cloyd J, et al. Margin status and long-term prognosis of primary pancreatic neuroendocrine tumor after curative resection: results from the US Neuroendocrine Tumor Study Group. Surgery. 2019;165:548-556.

16. Falconi M, Eriksson B, Kaltsas G, et al. ENETS consensus guidelines update for the management of patients with functional pancreatic 
neuroendocrine tumors and non-functional pancreatic neuroendocrine tumors. Neuroendocrinology. 2016;103:153-171.

17. Lin J-X, Huang C-M, Zheng $\mathrm{C}-\mathrm{H}$, et al. Is all advanced gastric cancer suitable for laparoscopy-assisted gastrectomy with extended lymphadenectomy? a case-control study using a propensity score method. Ann Surg Oncol. 2016;23:1252-1260.

18. Tokunaga M, Ohyama S, Hiki N, et al. Therapeutic value of lymph node dissection in advanced gastric cancer with macroscopic duodenum invasion: is the posterior pancreatic head lymph node dissection beneficial? Ann Surg Oncol. 2009;16:1241-1246.

19. Kosuga T, Ichikawa D, Okamoto $K$, et al. Survival benefits from splenic hilar lymph node dissection by splenectomy in gastric cancer patients: relative comparison of the benefits in subgroups of patients. Gastric Cancer. 2011;14:172-177.

20. Taki K, Hashimoto D, Nakagawa S, et al. Significance of lymph node metastasis in pancreatic neuroendocrine tumor. Surg Today. 2017;47:1104-1110.

21. Partelli S, Gaujoux S, Boninsegna L, et al. Pattern and clinical predictors of lymph node involvement in nonfunctioning pancreatic neuroendocrine tumors (NF-PanNETs). JAMA Surg. 2013;148:932-939.

22. Harimoto N, Hoshino K, Muranushi R, et al. Significance of lymph node metastasis in resectable well-differentiated pancreatic neuroendocrine tumor. Pancreas. 2019;48:943-947.
23. Sahara K, Tsilimigras DI, Pawlik TM. ASO author reflections: which patients benefit the most from lymphadenectomy during resection for intrahepatic cholangiocarcinoma? Ann Surg Oncol. 26, 2019: 2969-2970.

24. Lopez-Aguiar AG, Zaidi MY, Beal EW, et al. Defining the role of lymphadenectomy for pancreatic neuroendocrine tumors: an eightinstitution study of 695 patients from the US neuroendocrine tumor study group. Ann Surg Oncol. 2019;26:2517-2524.

25. Zhang XF, Xue F, Dong DH, et al. New nodal staging for primary pancreatic neuroendocrine tumors: a multi-institutional and national data analysis. Ann Surg. 2019. [published online ahead of print July 26, 2019].

How to cite this article: Wu L, Sahara K, Tsilimigras DI, et al. Therapeutic index of lymphadenectomy among patients with pancreatic neuroendocrine tumors: A multi-institutional analysis. J Surg Oncol. 2019;120:1080-1086.

https://doi.org/10.1002/jso.25689 